\title{
Comparison of diagnostic accuracy, time dependency, and prognostic impact of abnormal $Q$ waves, combined electrocardiographic criteria, and ST segment abnormalities in right ventricular infarction
}

Manfred Zehender, Wolfgang Kasper, Elisabeth Kauder, Martin Schönthaler, Manfred Olschewski, Hanjörg Just

\begin{abstract}
Objective-To determine the diagnostic and prognostic impact of abnormal $Q$ waves in comparison to or in combination with ST segment abnormalities in the right precordial and inferior leads as indicators of right ventricular infarction during the acute phase of inferior myocardial infarction.

Design-Prospective study of a consecutive series of 200 patients with acute inferior myocardial infarction with and without right ventricular infarction.

Setting-Department of internal medicine, university clinic.

Results-Right ventricular infarction was diagnosed in $106(57 \%)$ out of 187 patients from the results of coronary angiography, technetium pyrophosphate scanning, and measurement of haemodynamic variables or at necropsy, or both. In the acute phase of inferior infarction ST segment elevation $\geqslant 0.1 \mathrm{mV}$ in any of the right precordial leads V4-6R was the most reliable criterion for right ventricular infarction (sensitivity, 89\%; specificity, $83 \%$ ). Abnormal $Q$ waves in the right precordial leads, the most specific criterion (91\%) for right ventricular infarction, were superior to ST segment
\end{abstract}

elevation in patients admitted $>12$ hours after the onset of symptoms. Both ST segment elevation in leads V4-6R (increase in in hospital mortality, 6.2times; $P<0.001$; major complications, 2.3-times; $P<0.01$ ) and abnormal $Q$ waves (2.3-times, $P<0.05 ; 1 \cdot 8$-times, $P$ $<0.05$ ) on admission were highly predictive of a worse outcome during the in hospital period. In the presence of inferior myocardial infarction previously proposed combined electrocardiographic criteria were not better diagnostically or prognostically than ST segment abnormalities and abnormal $Q$ waves alone.

Conclusions-During the first 24 hours of inferior myocardial infarction ST segment elevation and abnormal $Q$ waves derived from the right precordial leads are complementary rather than competitive criteria for reliably diagnosing right ventricular infarction, both indicating a worse in hospital course for the patient. In this they are better than any other previously proposed combined electrocardiographic criteria in diagnosing right ventricular infarction. Right precordial leads should be routinely monitored in acute inferior myocardial infarction.

(Br Heart f 1994;72:119-124)

During recent years interest in right ventricular infarction as a complication of inferior myocardial infarction has spread beyond the deleterious effects on outcome. ${ }^{1-3}$ Diagnostic approaches for assessing right ventricular infarction include physical examination, ${ }^{46}$ echocardiography, ${ }^{46}$ first pass ${ }^{78}$ or equilibrium radionuclide ventriculography, ${ }^{10}$ technetium pyrophosphate scanning, ${ }^{1011}$ and haemodynamic measurements ${ }^{51213}$ but have increasingly focused on electrocardiography as the most simple and readily available diagnostic tool. ${ }^{14-25}$ Therefore, an increasing number of electrocardiographic criteria for right ventricular infarction have been proposed, including ST segment elevation or depression or abnormal $\mathbf{Q}$ waves in the right precordial, inferior, or left anterior leads either alone or in combination. Although we and many other working groups reported on the diagnostic accuracy of these criteria (table 1), ${ }^{24} 26$ there are no com- 
parative studies evaluating more than three of the criteria in the same patient population and little is known about the time dependency of these criteria in the acute and subacute phase of inferior myocardial infarction.

The prognostic impact of right ventricular infarction as shown by electrocardiographic criteria has been emphasised. Our study and that of Andersen et al followed up 136 patients with right ventricular infarction and found a close correlation between ST segment elevation in the right precordial lead V4R and a worse in hospital course of these patients. ${ }^{26}{ }^{27}$ Little is known, however, of the prognostic implications of any other previously proposed criteria. Thus, from the known transient character of ST segment elevation and the late admission of many patients with inferior myocardial infarction, the prognostic implications of abnormal $Q$ waves often seen in the right precordial leads beyond the acute infarction phase would be of great interest.

We prospectively studied 200 consecutive patients with acute inferior myocardial infarction to assess the diagnostic efficiency of 10 previously proposed electrocardiographic criteria using abnormal $Q$ waves and ST segment abnormalities in the right precordial and inferior leads in detecting right ventricular infarction compared with haemodynamic measurements and findings on, coronary angiography, technetium $99 \mathrm{~m}$-pyrophosphate scanning, and necropsy. We also determined their prognostic implications during the stay in hospital and three years of follow up.

\section{Patients and methods}

PATIENTS

From August 1985 to January 1990, we studied 200 consecutive patients with acute inferior myocardial infarction, which was diagnosed from the presence of typical chest pain lasting $>30$ minutes, an ST segment elevation of $>0.1 \mathrm{mV}$ in two or more leads of II, III, and aVF, and a rise in creatine kinase activity above twice normal values (>140 U/l) within the 24 hours after admission. There were 153 men and 47 women; their ages ranged from 35 to 91 years, with a mean of $61 \cdot 5(6)$ years. Thirty three patients had a history of myocardial infarction (anterior/lateral infarction, 21; posterior infarction; seven; inferior infarction; five). Six patients had a history of cardiac failure (New York Heart Association class III or IV).

After inclusion in the study 71 patients met the criteria ${ }^{28} 29$ for thrombolysis: they had had infarct symptoms lasting six or less hours, they were 75 or under, they had given their informed consent, and they had no contraindications for thrombolysis including having poorly controlled hypertension (systolic pressure $>180 \mathrm{~mm} \mathrm{Hg}$ or diastolic $>110 \mathrm{~mm} \mathrm{Hg}$ ), active bleeding, recent surgery or significant trauma, any cerebrovascular accident, or neoplasm. Patients with cardiogenic shock or cardiac arrest were included only if it was possible to stabilise their condition in the emergency room and to transfer them to the coronary care unit.

\section{ELECTROCARDIOGRAPHIC ASSESSMENT}

The results of standard 12 lead electrocardiography (leads I-III, aVR, aVL, aVF, V1-6) and right precordial surface electrocardiography (V3-6R) were documented immediately after admission to the hospital. In patients receiving thrombolysis electrocardiograms were obtained before drug administration. Six patients with pre-existing bundle branch block (four patients with left bundle branch block, two with right bundle branch block) were included in the study-all but one of these patients had a previous infarction.

ST segment elevation or depression (by $\geqslant$ $0.1 \mathrm{mV}$ ) was assessed $0.04 \mathrm{~s}$ after the $\mathrm{J}$ point in all 16 leads; the presence of abnormal $Q$ waves $(\geqslant 0.04 \mathrm{~s})$ was analysed in II, III, aVF, and right precordial leads. Three consecutive $\mathrm{QRS}$ complexes were measured using the $\mathrm{PQ}$ level as the isoelectric line. All analyses were performed by a cardiologist unaware of the clinical status of the patient; electrocardiograms were classified according to the criteria of the Manhattan code. The following electrocardiographic criteria were additionally studied: ST segment elevation $(\geqslant 0.1 \mathrm{mV})$ in any of leads V3-6R, Lopez-Sendon criterion (ST segment elevation in V4R $>$ V1-3), ${ }^{19}$ abnormal $Q$ waves ( $\geqslant 0.04 \mathrm{~s}$ ) in any of leads V3-4R, Candell criterion (abnormal $Q$ wave and ST elevation in more than one lead in V3-6R), ${ }^{30}$ and Andersen criterion (ST segment elevation in lead II $>0.1 \mathrm{mV}$ and III $/ \mathrm{II}>1 \mathrm{mV}$ ). ${ }^{15}$

DIAGNOSTIC EVALUATION

Right ventricular infarction was diagnosed (a) if there were wall abnormalities, or occlusion (or $\mathbf{9 0 0 \%}$ stenosis) of the right coronary artery proximal to the right ventricular branch, or both, on ventriculography and coronary angiography; $(b)$ if there was necroscopic evidence of such infarction; $(c)$ if there was focal uptake of label on technetium- $-99 \mathrm{~m}$ pyrophosphate imaging ${ }^{11}$; or $(d)$ if right atrial pressure was greater than or equal to pulmonary capillary pressure or showed a strongly non-compliant pattern. ${ }^{13}$

Haemodynamic measurements and technetium-99m pyrophosphate imaging were considered only when performed during acute phase of myocardial infarction (up to 24 hours); results from coronary angiography or from ventriculography were performed during hospital stay. Sensitivity (percentage of patients with right ventricular infarction correctly identified by an electrocardiographic criterion), specificity (percentage of patients without right ventricular infarction and not meeting an electrocardiographic criterion), and diagnostic efficiency of ST elevation in V4R (patients with and without right ventricular infarction correctly identified by an electrocardiographic criterion) were calculated for each of the four diagnostic tests. Overall diagnostic accuracy was calculated by using the results of the first test in each patient according 
to the above sequence. This included findings at necropsy in 18 patients, angiographic and ventriculographic findings in 112 patients, results from technetium-99m pyrophosphate imaging in 37 patients, and haemodynamic findings in 20 patients. In $88 \%$ of the patients with at least two diagnostic tests diagnostic findings were similar. Thirteen patients in whom none of the four tests could be adequately performed for different reasons (early death, technical reasons) were excluded from further analysis.

\section{PROGNOSTIC EVALUATIONS}

The in hospital course was determined in all patients in terms of mortality and the presence of major in hospital complications, including ventricular fibrillation, sustained ventricular tachycardia $(>30 \mathrm{~s}$ or causing haemodynamic intolerance), cardiogenic shock, myocardial rupture, third degree atrioventricular block, and the need for external or permanent cardiac pacing for other bradyarrhythmias. During the first year after discharge prognostic evaluation included death, fatal or non-fatal myocardial infarction, and the need for pacemaker implantation and for coronary revascularisation.

\section{STATISTICAL ANALYSIS}

All pooled data are expressed as means (SD). Differences between groups were analysed using the standard $\chi^{2}$ test, the non-paired $t$ test, and one way analysis of variance whenever appropriate. All tests of significance were two tailed and used a significance level of $5 \%$.

\section{Results}

Overall, 106 out of 187 patients (57\%) had right ventricular infarction according to findings on coronary angiography, ventriculography, and scintigraphy.

\section{DIAGNOSTIC ACCURACY OF SINGLE AND} COMBINED ELECTROCARDIOGRAPHIC CRITERIA FOR RIGHT VENTRICULAR INFARCTION

Table 2 summarises the prevalences of the 10 electrocardiographic criteria in the 187 patients. ST segment elevation in any of the

Table 2 Prevalence and diagnostic efficiency of different electrocardiographic criteria for right ventricular infarction in one hundred and eighty seven patients with acute inferior myocardial infarction

\begin{tabular}{|c|c|c|c|c|}
\hline $\begin{array}{l}\text { Electrocardiographic } \\
\text { criterion }\end{array}$ & $\begin{array}{l}\text { Prevalence } \\
\text { (No of } \\
\text { patients (\%)) }\end{array}$ & $\begin{array}{l}\text { Sensitivity } \\
\text { (No of } \\
\text { patients (\%)) }\end{array}$ & $\begin{array}{l}\text { Specificity* } \\
\text { (No of } \\
\text { patients (\%)) }\end{array}$ & $\begin{array}{l}\text { Positive predictive } \\
\text { value (no of } \\
\text { patients (\%)) }\end{array}$ \\
\hline $\begin{array}{l}\text { V3R }(\geqslant 0.1 \mathrm{mV}) \\
\text { V4R }(\geqslant 0.1 \mathrm{mV}) \\
\text { V5R }(\geqslant 0.1 \mathrm{mV}) \\
\text { V6R }(\geqslant 0.1 \mathrm{mV}) \\
\text { V4-6R }(\geqslant 0.1 \mathrm{mV})\end{array}$ & $\begin{array}{c}\text { egment elevation } \\
77(41) \\
101(54) \\
101(54) \\
97(52) \\
103(55)\end{array}$ & $\begin{array}{l}n \text { right precordia } \\
64(63) \\
88(89) \\
81(80) \\
80(79) \\
92(91)\end{array}$ & $\begin{array}{l}\text { leads V3-6R } \\
72(86) \\
70(83) \\
68(81) \\
68(81) \\
66(79)\end{array}$ & $\begin{array}{l}136(74) \\
158(85) \\
149(81) \\
148(80) \\
158(85)\end{array}$ \\
\hline $\begin{array}{l}\text { V4R }(>0.04 \mathrm{~s}) \\
\text { V3-4R }(>0.04 \mathrm{~s})\end{array}$ & $\begin{array}{l}\text { Abnormal } Q \text { wa } \\
67(36) \\
69(37)\end{array}$ & $\begin{array}{l}\text { e in right precorc } \\
59(58) \\
60(59)\end{array}$ & $\begin{array}{l}\text { ial leads } \\
78(93) \\
77(92)\end{array}$ & $\begin{array}{l}137(74) \\
143(77)\end{array}$ \\
\hline $\begin{array}{l}\text { Lopez-Sendon criterion }{ }^{19} \\
\text { Candell criterion }^{30} \\
\text { Andersen criterion }^{15}\end{array}$ & $\begin{array}{l}\text { Combined elec } \\
99(53) \\
62(33) \\
170(91)\end{array}$ & $\begin{array}{l}\text { rocardiographic } \\
88(87) \\
54(54) \\
96(95)\end{array}$ & $\begin{array}{l}\text { riteria } \\
77(92) \\
7(92) \\
11(13)\end{array}$ & $\begin{array}{l}165(89) \\
131(71) \\
107(58)\end{array}$ \\
\hline
\end{tabular}

* Based on 187 patients who had complete diagnostic test results or in whom necroscopic findings were available. right precordial leads was observed in $41-55 \%$ of patients but was present in only six out of 33 patients $(18 \%, P<0.001)$ admitted late $(>12$ hours after the onset of symptoms). The prevalence of abnormal $Q$ waves increased from 51 out of 154 patients (33\%) to 18 out of $33(55 \%, P<0.05)$ when patients with early and late admission were compared. Combined electrocardiographic criteria for right ventricular infarction were met by $43-53 \%$ of patients when using the right precordial leads, and by $91 \%$ of patients when ST segment elevation in leads II and III was used for calculation (table 2).

Table 2 also shows the diagnostic power of the 10 electrocardiographic criteria. Positive predictive values were highest when ST segment elevation $\geqslant 0.1 \mathrm{mV}$ in lead V4R, or in any of leads V3-6R, was considered (85\%). Diagnostic accuracy did not further improve when the extent of ST segment elevation was considered using any cut off point from 0.05 $\mathrm{mV}$ to $0.2 \mathrm{mV}$. Abnormal $\mathrm{Q}$ waves in the right precordial leads showed a higher diagnostic specificity ( $>90 \%)$, but sensitivity was low (58-59\%), mainly because most patients were admitted early after the onset of symptoms. In the 33 patients admitted late after the onset of symptoms abnormal $Q$ waves had a sensitivity of $95 \%$ and a specificity of $93 \%$ for showing right ventricular infarction. In the presence of inferior myocardial infarction none of the combined electrocardiographic criteria for evidencing right ventricular infarction was superior to right precordial ST segment elevation or abnormal $Q$ waves alone (table 2 ).

Diagnostic accuracy of ST segment elevation and abnormal $Q$ waves was not altered in the small subgroup of patients with a history of myocardial infarction, pre-existing bundle branch block, or heart failure.

CLINICAL AND PROGNOSTIC IMPACT OF SINGLE AND COMBINED ELECTROCARDIOGRAPHIC CRITERIA FOR SHOWING RIGHT VENTRICULAR INFARCTION

During the time in hospital 38 of the 200 patients $(19 \%)$ with acute inferior myocardial infarction died. Ninety four patients (47\%) suffered major complications, including cardiogenic shock (31 (16\%)), ventricular fibrillation (31 $(16 \%))$, sustained ventricular tachycardia (24 (12\%)), second degree Mobitz type and third degree atrioventricular block (28 (14\%)), pacing requirement (22 $(11 \%)$, and myocardial rupture or tamponade (nine $(5 \%)$ ).

The figure shows the severity of ST segment elevation or depression and of abnormal $Q$ waves in the 15 electrocardiographic leads according to outcome in hospital. Outcome was significantly worsened by a greater ST segment elevation and especially by deeper abnormal $Q$ waves in leads V3-6R. ST segment elevation or depression or abnormal $Q$ waves in the standard leads were not useful in distinguishing patients with and without in hospital complications.

In univariate analysis ST segment elevation $\geqslant 0.1 \mathrm{mV}$ in the right precordial leads 

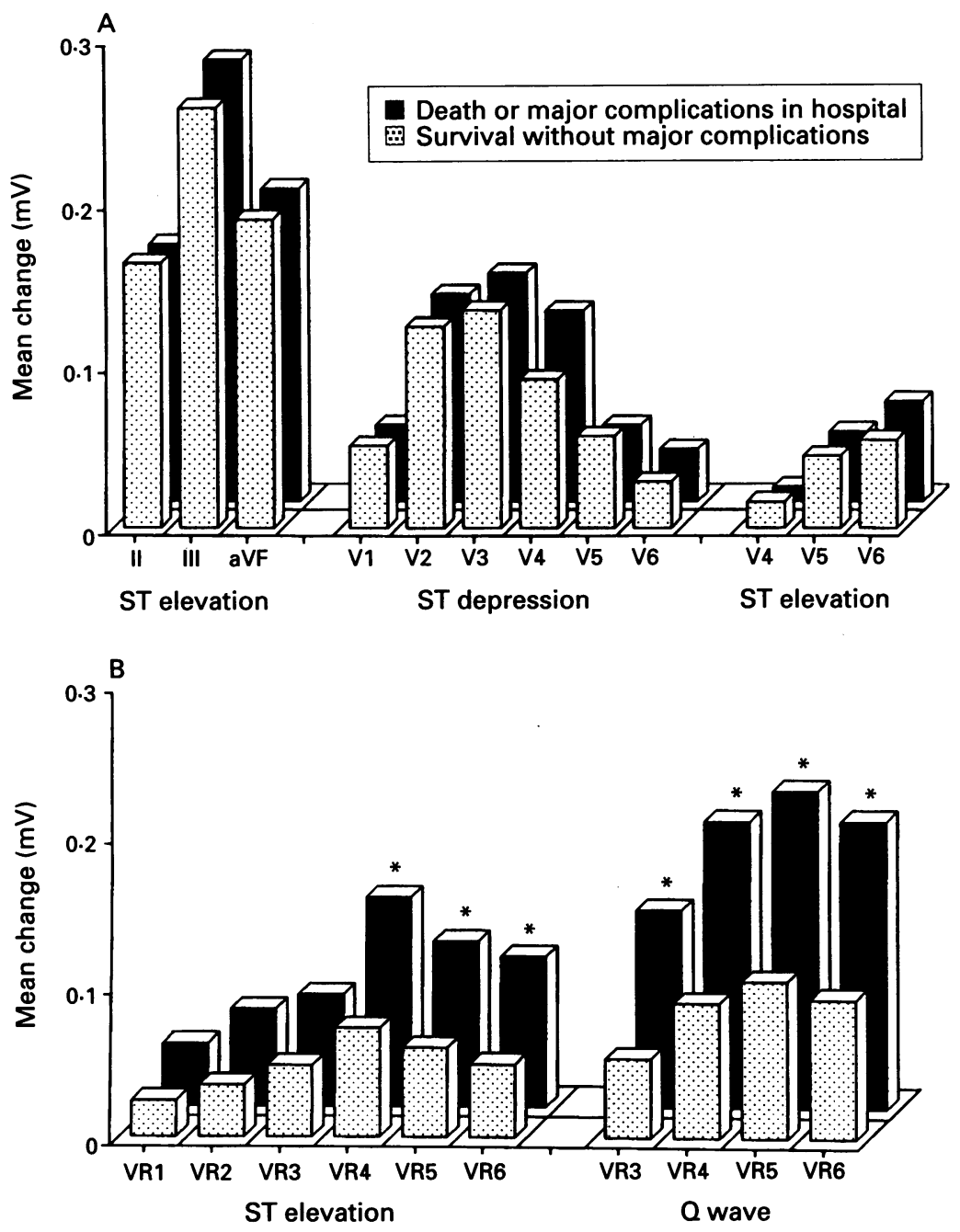

(A) Mean ST segment changes in leads II, III, aVF, and the left precordial leads V1-6 and $(B)$ mean $S T$ elevation and abnormal $Q$ waves in right precordiol leads V1-6R according to whether patients died or had major complications in hospital. Total number of patients is 187.

$\star P<0.05$

(V4-6R) predicted a 6.2-times higher in hospital mortality $(\mathrm{P}<0.001)$ and a 2.3 -times higher rate of major in hospital complications $(P<0.01)$ (table 3). Prognostic relevance was also shown for the presence of abnormal $Q$ waves in the right precordial leads V3-4R (mortality increase, 2.3-times, $\mathrm{P}<0.01$;

Table 3 Univariate analysis of mortality and incidence of major complications during stay in hospital for acute inferior myocardial infarction as stratified by electrocardiographic criteria

\begin{tabular}{|c|c|c|c|c|}
\hline \multirow[b]{2}{*}{ Electrocardiographic criterion } & \multicolumn{2}{|c|}{$\begin{array}{l}\text { Mortality (\%) } \\
\text { when criterion: }\end{array}$} & \multicolumn{2}{|c|}{$\begin{array}{l}\text { Incidence of major complications } \\
(\%)+\text { when criterion: }\end{array}$} \\
\hline & Present & Absent & Present & Absent \\
\hline $\begin{array}{l}\text { V3R } \\
\text { V4R } \\
\text { V5R } \\
\text { V6R } \\
\text { V4-6R }\end{array}$ & $\begin{array}{c}\text { tion }>0.1 \\
30 \\
31 \\
31 \\
32 \\
30\end{array}$ & $\begin{array}{c}\text { right pre } \\
12^{\star} \\
6^{\star \star} \\
5^{\star \star} \\
5^{\star \star} \\
5^{\star \star}\end{array}$ & $\begin{array}{l}\text { l leads } \\
62 \\
64 \\
64 \\
65 \\
61\end{array}$ & $\begin{array}{l}34^{\star \star} \\
28^{\star \star} \\
29^{\star \star} \\
28^{\star \star} \\
30^{\star \star}\end{array}$ \\
\hline $\begin{array}{l}\text { V4R } \\
\text { V3-4R }\end{array}$ & $\begin{array}{l}2 \text { wave in } \\
30 \\
30\end{array}$ & $\begin{array}{l}\text { ecordial h } \\
13^{\star} \\
13^{\star}\end{array}$ & $\begin{array}{l}65 \\
66\end{array}$ & $\begin{array}{l}37^{\star \star} \\
36^{\star \star}\end{array}$ \\
\hline $\begin{array}{l}\text { Candell criterion }{ }^{30} \\
\text { Lopez-Sendon criterion } \\
\text { Andersen criterion }^{15}\end{array}$ & $\begin{array}{l}32 \\
31 \\
20\end{array}$ & $\begin{array}{c}\text { criteria } \\
10^{\star} \\
5^{\star \star} \\
11\end{array}$ & $\begin{array}{l}60 \\
62 \\
48\end{array}$ & $\begin{array}{l}37^{\star \star} \\
30^{\star \star} \\
33\end{array}$ \\
\hline
\end{tabular}

†Cardiogenic shock, ventricular fibrillation or sustained tachycardia, second or third degree antrioventricular block, severe bradycardia, pacing required, myocardial rupture. ${ }_{\star} \mathrm{P}<0.01,{ }^{\star \star \mathrm{P}}<0.001$ (univariate analysis). major complications, 1.8 -times, $P<0.01)$. Mortality was highest in patients who met the Candell criterion; this criterion, however, missed many patients with a worse prognosis who presented only with ST segment elevation or abnormal $Q$ waves. None of the combined criteria showed overall prognostic superiority (table 3 ). Multivariate analysis showed that the prognostic implications of ST segment elevation (mortality, $P=0.0002$; major complications, $P=0.0001$ ) and abnormal $Q$ waves (mortality, $P=0.0293$; major complications, $P=0.001$ ) were independent of clinical variables, such as age, sex, size of myocardial infarction, prehospital complications, thrombolysis, and history of myocardial infarction.

During the first year after discharge from hospital, cardiac death ( $7 \% v 6 \%)$, sudden cardiac death $(5 \% v 3 \%)$, reinfarction $(17 \% v$ $10 \%$ ), and need for revascularisation such as bypass grafting or balloon angioplasty $(28 \% v$ $28 \%$ ) were similar in patients with and without right ventricular infarction during acute inferior myocardial infarction. The need for permanent pacing increased 5-6 fold in the presence of ST segment elevation or abnormal $Q$ waves.

\section{Discussion}

Our study shows that both ST segment elevation and abnormal $Q$ waves in the right precordial leads are of diagnostic and prognostic value when observed during the first 24 hours after the onset of symptoms of infarction. Although right precordial ST segment elevation was a sensitive and specific marker of right ventricular infarction in the early phase of infarction, abnormal $Q$ waves were superior in patients admitted more than 12 hours after the onset of symptoms. Presence of any of the two criteria and especially the combination of both was associated with a worse in hospital prognosis. Previously proposed combined electrocardiographic criteria were not better diagnostically or prognostically in patients with acute inferior myocardial infarction.

Right ventricular infarction complicates acute inferior myocardial infarction in $19-51 \%$ of patients. ${ }^{31-33}$ Its early recognition is clinically relevant because of the increased incidence of major complications in these patients, ${ }^{451}$ subsequently leading to a higher in hospital mortality. ${ }^{33-37}$ During recent years an increasing number of electrocardiographic criteria has been proposed to show right ventricular infarction to overcome the logistical and methodological problems and the time delay inherent in the use of more complex tests, such as cardiac angiography, ${ }^{238}$ scintigraphic imaging, ${ }^{7-11}$ and haemodynamic measurements..$^{51213}$ The most extensively studied electrocardiographic criterion for right ventricular infarction is ST segment elevation in lead V4R, which is effective in diagnosing acute right ventricular infarction, 18232426273039 as well as predicting prognostic outcome in patients with acute inferior myocardial infarction. ${ }^{2627}$ 
To improve diagnostic and prognostic accuracy still further, however, an increasing number of additional electrocardiographic criteria using ST segment elevation of different extent and in different right precordial leads, as well as abnormal $Q$ waves and a combination of both, has been proposed (table 1). Thus, the sensitivity of ST segment elevation was increased when its presence in any of leads V4-6R was considered ${ }^{16}$ or a smaller elevation was used-for example, $0.05 \mathrm{mV} .{ }^{1922} 23$ Owing to a lower specificity, however, these studies failed to increase overall diagnostic efficiency. To improve specificity, Morgera et al and Lopez-Sendon et al proposed using the presence of abnormal Q/QS waves in the right precordial leads for diagnosing right ventricular infarction. ${ }^{1923}$ This criterion was considered to be of particular interest in patients admitted late after the onset of infarction symptoms because ST segment elevation is transient in most patients. ${ }^{1824}$ In the only three studies looking at abnormal $Q$ waves in the right precordial leads sensitivity (37-94\%) and specificity (59\%-100\%) varied widely, 141923 but these studies were limited by including fewer than 60 patients with right ventricular infarction. More recently, Andersen et al, reported the value of another electrocardiographic criterion using the ratio of ST segment elevation in leads II and III to show right ventricular infarction. ${ }^{15}$

Apart from ST segment elevation in lead V4R, however, data on the diagnostic accuracy of the other proposed electrocardiographic criteria are rare and have not been evaluated in a prospective and comparative study in the same patient population; also data are not available on the prognostic implications of these criteria. We therefore assessed such information in 187 consecutive patients with acute inferior myocardial infarction, in whom a diagnostic work up, including coronary angiography, technetium pyrophosphate imaging, haemodynamic measurements, and findings at necropsy, indicated the presence of right ventricular infarction in $57 \%$ of patients. There were only minor differences in the diagnostic and prognostic impact when ST segment elevation either in lead V4R or in any of leads V4-6R was chosen. Overall, diagnostic accuracy was not increased, by selecting any criteria other than 0.05 to $0.2 \mathrm{mV}$ for the extent of ST segment elevation. ${ }^{1922} 23$ ST segment elevation, however, increasingly failed to show right ventricular infarction when patients were admitted to the hospital late after the onset of infarction symptoms. Because of the development of myocardial necrosis in these patients abnormal $Q$ waves subsequently replaced ST segment elevation. Under these circumstances, therefore, abnormal $Q$ waves were a highly sensitive and specific criterion for right ventricular infarction.

Independently of when they were observed, abnormal $Q$ waves within the first 24 hours after the onset of symptoms were associated with a worse in hospital course. Mortality and complication rate were both doubled. This is somewhat lower than the prognostic impact previously reported for ST segment elevation in lead V4R ${ }^{26} 27$ and, as shown in this study, in any of leads V4-6R. The presence of abnormal $Q$ waves may, however, be particularly helpful when patients are admitted late after the onset of symptoms and they no longer have ST segment elevation. Therefore abnormal $Q$ waves and ST segment elevation should be considered as complimentary rather than competitive criteria, both carrying prognostically relevant information.

All combined electrocardiographic criteria proposed to improve the diagnostic accuracy of right precordial ST segment elevation ${ }^{15} 1928$ failed to do so in this study. When compared with previous work, this lack could be because we included only patients with inferior myocardial infarction, ${ }^{19}$ because we could not confirm previously reported results, ${ }^{15}$ or because the proposed criterion was too restrictive, resulting in high specificity but low sensitivity. ${ }^{30}$ Similarily, none of these criteria was better overall superiority in predicting prognosis.

Long-term follow up over three years showed a high incidence of cardiovascular events, but none of the above mentioned criteria for diagnosing right ventricular infarction was helpful in stratifying the patient's outcome after discharge from hospital, except for the need for permanent pacemaker implantation.

LIMITATIONS OF OUR STUDY

ST segment elevation in the right precordial leads V3-6R is represented by a rightward and anteriorly oriented vector; thus leftward ST segment deviation as seen in the lateral left precordial leads for a lateral infarction may cancel out the ST segment elevation in the right precordial leads. In our study only $36 \%$ of patients were given thrombolysis, which is similar to the percentages in previous reports. ${ }^{28} 29$ Thrombolysis was not relevant when the diagnostic and prognostic implications of different criteria for right ventricular infarction were compared.

\section{CONCLUSION}

In acute inferior myocardial infarction ST segment elevation in leads V4-6R and abnormal $Q$ waves in the right precordial leads should be considered as complimentary, rather than competitive, criteria for diagnosing right ventricular infarction during the 24 hours after the onset of symptoms. ST segment elevation during the acute phase of infarction and abnormal $Q$ waves more than 12 hours after the onset of pain both carry important prognostic information for the in hospital course in these patients. The extent of ST segment elevation, as well as combined electrocardiographic criteria, do not further increase the overall diagnostic accuracy and prognostic impact of these criteria. Assessment of a right precordial electrocardiogram should be routine in all patients presenting with acute inferior myocardial infarction. 
1 Cohn JN. Right ventricular infarction revisited. $\mathrm{Am} f$ Cardiol 1979;33:666-8.

2 Isner JM. Right ventricular myocardial infarction. In: Konstam AM, Isner JM, eds. The right ventricle. Amsterdam: Kluwer, 1988:87-129.

3 Berger PB, Ryan TJ. Inferior myocardial infarction. Highrisk subgroups. Circulation 1990;81:401-11.

4 Lopez-Sendon J, Garcia-Fernandez MA, Coma-Canella I Yanguela MM, Banuelos F. Segmental right ventricular function after acute myocardial infarction: two-dimensional echocardiographic study in 63 patients. Am $f$ Cardiol 1983;51:390-6.

5 Dell'Italia LJ, Starling MR, O'Rourke RA. Physical examination for exclusion of hemodynamically important righ ventricular infarction. Ann Intern Med 1983;99:608-1

6 Dell'Italia LJ, Starling MR, Crawford MH, Boros BL, Chaudhuri TK, O'Rourke RA. Right ventricular infarction: identification by hemodynamic measurements before and after volume loading and correlation with non-invasive techniques. $f \mathrm{Am}$ Coll Cardiol 1984;4 931-9.

7 Reduto LA, Berger HJ, Cohen LS, Bottschalk A, Zaret BC. Sequential radionuclide assessment of left and right ventricular performance after acute transmural
dial infarction. Ann Intern Med 1978;89:441-7.

8 Starling MR, Dell'Italia LJ, Chandhuri TK, Boros BL O'Rourke RA. First transit and equilibrium radionuclide angiography in patients with inferior transmural myocarangiography in pation hemodynamically significant right ventricular infarction. $\mathcal{F}$ Am Coll Cardiol 1984;4:923-30.

9 Shah PK, Maddahi J, Berman DS, Pichler M, Swan HJC Scintographically detected predominant right ventricular dysfunction in acute myocardial infarction: clinical and
hemodynamic correlates and implications for therapy hemodynamic correlates and implications for ther

10 Nishumura T, Yasuda T, Gold HK, Leinbach RC Boucher CA, McKusick KA, et al. High-risk subgroup of inferior infarction. Importance of anterior wall motion and right ventricular function. Radiol Med (Torino) 1986;4:112-8

11 Wackers FJ, Lie KI, Sokole EB, Res J, Schoot JB, Durrer D. Prevalence of right ventricular involvement in inferio wall infarction assessed with myocardial imaging with thallium-201 and technetium-99 m pyrophosphate. $A m$ $f$ Cardiol 1978;42:358-62.

12 Lloyd EA, Gersh BJ, Kennelly BM. Hemodynamic spectrum of "dominant" right ventricular infarction in 19 patients. Am 7 Cardiol 1981;48:1016-22.

13 Lopez-Sendon J, Coma-Canella I, Gamallo C. Sensitivity and specificity of hemodynamic criteria in the diagnosis of acute myocardial infarction. Circulation 1981;64:515-25.

14 Andersen HR, Falk E, Nielsen D. Right ventricular infarction: diagnostic accuracy of electrocardiographic right chest leads V3R to V7R investigated prospectively in 43 consecutive fatal cases from a coronary care unit. $\mathrm{Br}$ consecutive fatal cases

15 Andersen HR, Nielsen D, Falk E. Right ventricular infarction: diagnostic value of ST elevation in lead III exceeding that of lead II during inferior/posterior infarction and ing that of lead II during inferior/posterior infarction and
comparison with right chest leads V3R to V7R. $A m$ comparison with right

16 Croft $\mathrm{CH}$, Nicod P, Corbett JR, Lewis SE, Huxley $R$, Mukharji J, et al. Detection of acute right ventricular infarction by precordial electrocardiography. $A m \mathcal{J}$ Cardiol 1982;50:421-7.

17 Geft IL, Shah PK, Rodriguez L, Hulse S, Maddahi J, Berman DS, et al. ST elevations in lead V1-5 may be caused by right coronary artery occlusion and acute righ ventricular infarction. Am $\mathcal{F}$ Cardiol 1984;53:991-6.

18 Braat S, Brugada $P$, deZwaan $C$, DenDulk $K$, Wellen HJJ. Right and left ventricular ejection fraction in acute inferior wall infarction with or without ST segment elevation in lead V4R. 7 Am Coll Cardiol 1984;4:940-4.

19 Lopez-Sendon J, Coma-Canella I, Alcasena S, Seoane J, Gamallo C. Electrocardiographic findings in acute right ventricular infarction: sensitivity and specificity of electrocardiographic alterations in right precordial leads V4R, V.

20 Lew AS, Laramee P, Shah PK, Maddahi J, Peter T, Ganz W. Ratio of ST-segment depression in lead V2 to ST segment elevation in lead aVF in evolving inferior acute myocardial infarction: an aid to the early recognition of right ventricular ischemia. Am f Cardiol 1986;57: right venti

21 Chou T, Bel-Khan J, Allen J, Brockmeier L, Fowler NO.
Electrocardiographic diagnosis of right ventricular infarction. $A m \mathcal{F}$ Med 1981;70:1175-80.

22 Klein HO, Tordjman T, Ninio R, Sareli P, Oren V, Lang R, $e t$ al. The early recognition of right ventricular infarction. Diagnostic accuracy of the electrocardiographic V4R lead. Circulation 1983;67:558-65.

23 Morgera T, Albert E, Silvestri F, Pandullo C, Della Mea MT, Camerini F. Right precordial ST and QRS changes in the diagnosis of right ventricular infarction. Am Heart $\mathcal{f}$ 1984;108:13-8.

24 Braat SH, Brugada P, De Zwann C, Coenegracht JM, Wellens HJ. Value of electrocardiogram in diagnosing right ventricular involvement in patients with an acute inferior wall myocardial infarction. Br Heart $\mathcal{f}$ 1983;49: 368-72.

25 Robalino BD, Whitlow PL, Underwood DA, Salcedo EE. Electrocardiographic manifestations of right ventricular infarction. Am Heart $\mathcal{F}$ 1988;118:138-44.

26 Zehender M, Kasper W, Kauder E, Schönthaler M, Geibel $A$, Olschewski $M$, et al. Right ventricular infarction as an independent predictor of prognosis after acute inferio myocardial infarction. N Engl f Med 1993;328:981-8.

27 Andersen HR, Dorthe Nielsen D, Lund O, Falk E. Prognostic significance of right ventricular infarction diagnosed by ST elevation in right chest leads V3R to V7R. Int $¥$ Cardiol 1989;23:349-56.

28 Grines CL, DeMaria AN. Optimal utilization of thrombolytic therapy for acute myocardial infarction: concepts and controversies. F Am Coll Cardiol 1990;16:223-31.

29 Califf RM, Mark DB, Wagner GS. Acute coronary care in the thrombolytic era. Chicago: Yearbook Medical the thrombolytic era.

30 Candell-Riera J, Fiqueras J, Valle V, Alvarez A, Gutierrez $\mathrm{L}$, Cortadellas J, et al. Right ventricular infarction: relat) Cortadellas J, et al. Right ventricular infarction: relationship between ST segment elevation in V4R and hemodynamic, scintigraphic, and echocardiographic findings in patients with acute inf

31 Isner JM, Roberts WC. Right ventricular infarction complicating left ventricular infarction secondary to coronary artery disease. Frequency, location, associated findings and significance from analysis of 236 necropsy patients with acute or healed myocardial infarction. Am $\mathcal{f}$ Cardiol 1978;42:885-94.

32 Ratliff NB, Hackel DB. Combined left and right ventricular infarction: pathogenesis and clinicopathologic correlations. Am f Cardiol 1980;45:217-21.

33 Wilcox RG, Olsson CG, Skene AM, von der Lippe G, Jensen G, Hampton JR, for the ASSET Study Group. Trial of tissue plasminogen activator for mortality reduction in acute myocardial infarction. Lancet 1988;i: 525-30.

34 Cragg DR, Bonema JD, Jaiyesimi IA. Ineligibility for intravenous thrombolytic therapy predicts high mortality after myocardial infarction [abstract]. Circulation 1989; 80(suppl II):II-552.

35 Weaver WD, Martin J, Litwin P, Eisenberg M, Ho M, Kudenchuk $P$, for the MITI Project Investigators. Prehospital thrombolytic therapy-MITI project report on phase I: feasibility, characteristics of patients [abstract]. F Am Coll Cardiol 1989;13(suppl A):152A

36 Bates ER, Clemmensen PM, Califf RM, Gorman LE, Aronson LG, George BS, et al. Precordial ST segment depression predicts a worse prognosis in inferior infarction despite reperfusion therapy. $\mathcal{F} \mathrm{Am}$ Coll Cardiol 1990;16:13538-44.

37 Nasmith J, Marpole D, Rahal D, Homan J, Stewart S, Sniderman A. Clinical outcomes after inferior myocardial infarction. Ann Intern Med 1982;96:22-6.

38 Bough EW, Korr KS. Prevalence and severity of circumflex coronary artery disease in electrocardiographic posterior myocardial infarction. $\mathcal{F} \mathrm{Am}$ Coll Cardiol 1986;7: $990-6$.

39 Ehrhard LR, Sjogren A, Wahlberg I. Single right-sided precordial lead in the diagnosis of right ventricular
involvement in inferior myocardial infarction. Am Heart $\mathcal{F}$ 1976;91:571-6.

40 Coma-Canella I, Lopez-Sendon K, Alcasena S, Garcia C, Gamallo C, Jadraque LM. Electrocardiographic alterations in leads V1 to V3 in the diagnosis of right and left ventricular infarction. Am Heart f 1986;112:940-6.

41 Lew AS, Laramee P, Shah PK, Maddahi J, Peter T, Ganz W. Ratio of ST-segment depression in lead V2 to STsegment elevation in lead aVF in evolving inferior acute myocardial infarction: an aid to the early recognition of myocardial infarction: an aid to the early recognition of right ven $1047-51$. 